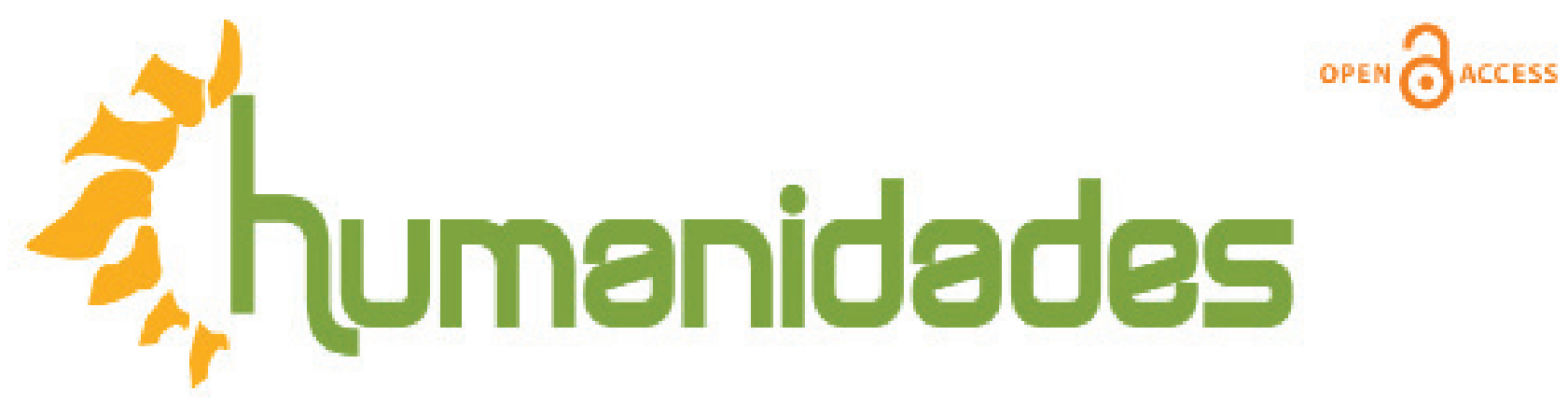

Revista de la Escuela de Estudios Generales, Universidad de Costa Rica

Enero-julio, 2019 •Volumen 9, número 1 • EISSN 2215-3934•pp. 1-28

Recibido: 1-Agosto-2018 Aceptado: 6-Setiembre-2018

\title{
Identidades «obscenas». Tras las huellas subjetivas de la actriz porno contemporánea
}

DOI: https://doi.org/10.15517/h.v9i1.35289

\section{Jorge Marchena Sanabria}

Máster, docente de la Universidad de Costa Rica - Sede de Occidente, Centro de Investigaciones en Identidad y Cultura Latinoamericanas (CIICLA), Costa Rica.

Correo electrónico: jorge.marchena@ucr.ac.cr

Todos los derechos reservados. Universidad de Costa Rica. Esta revista se encuentra licenciada con Creative Commons. Reconocimiento-NoComercial-SinObraDerivada 3.0 Costa Rica. Correo electrónico: humanidades@ucr.ac.cr/ Sitioweb: http: //revistas.ucr.ac.cr/index.php/ humanidades 


\section{Identidades «obscenas». Tras las huellas subjetivas de la actriz porno contemporánea}

\section{Resumen}

El presente ensayo analiza la formación de subjetividades que la pornografía está promoviendo en las últimas décadas, sobre todo, a través de la promoción de agresivas visiones patriarcales y heteronormadas. Un aspecto relevante es que el porno se encuentra en pleno proceso de «normalización», es decir, se está convirtiendo en una parte esencial de la vida cotidiana y en modelador de comportamientos y prácticas sexuales; máxime en sociedades conservadoras con deficientes niveles de educación o concientización en la materia. Para la elaboración de este trabajo se partió de una revisión preliminar de documentales que abordan el tema, para luego centrarse en distintas tesis feministas que han discutido sobre la problemática desde la década de 1970. Al final del escrito se enfatiza que aunque el porno puede presentar una fuerte capacidad transgresora, se ha reducido a nuevos mecanismos de represión subjetiva y sexual.

\section{«Obscene» Identities. Following the Subjective Traces of the Contemporary Porn Actress}

\begin{abstract}
This essay analyzes the formation of subjectivities that pornography is promoting in the last decades, above all, through the promotion of aggressive patriarchal and heteronormal visions. One relevant aspect is that porn is in the process of «normalization», that is, it is becoming an essential part of everyday life and modeling sexual behaviors and practices; especially in conservative societies with poor levels of education or awareness in the field. For the preparation of this work was based on a brief review of documentaries that address the issue, then focus on different feminist thesis that have discussed the problem since the 1970s. At the end of the writing emphasizes that although porn can present a strong transgressive capacity, it has been reduced to new mechanisms of subjective and sexual repression.
\end{abstract}

Palabras clave:

subjetividad, pornografía, mujer, feminismo, cosificación

Keywords:

subjectivity, pornography, women, feminism, reification 


\section{Introducción}

El presente ensayo debe comenzar de la forma más inapropiada: disculpándose de antemano, ya que es muy probable que al finalizar no se haya logrado abordar satisfactoriamente el tema. Por supuesto, es indispensable introducir y explicar en qué consiste la propuesta, así como los alcances y límites de esta. El objetivo central es comprender cómo se construyen las subjetividades ${ }^{1}$ de la actriz porno, especialmente, enfocado en ¿cuáles son las representaciones dominantes de la mujer en la pornografía contemporánea? Es claro que esta es una tarea difícil y que lo máximo que se puede lograr son meras aproximaciones.

Igualmente, diseccionar la pregunta y cuestionar pre-concepciones tendrá mejores resultados. Dadas las distancias geográficas, idiomáticas y de contexto en general -el grueso de la industria se encuentra en Estados Unidos y Europa-, sumando lo difícil que sería lograr obtener una entrevista con una de estas profesionales; en conjunto, ante estas limitaciones, la fuente primaria para explorar el mundo del porno se torna elusiva. De este modo, el punto de partida es dual, primero, lo poco que realmente sabemos del llamado porno, puesto que verlo o consumirlo se aleja mucho de comprenderlo. En segundo término, partimos de los datos que pudimos recopilar de una serie de documentales recientes, tales como Hot Girls Wanted (documental y serie de seis episodios) y After porn ends (dos entregas) ${ }^{2}$. Dado que no se pretende analizar profundamente cada una de estas propuestas, ofrecemos una pequeña síntesis conjunta. Para describir las citadas obras se puede comenzar anotando que el grueso de ellas es una variante de testimonios y detrás de cámaras de actrices estadounidenses y algunas europeas, la mayor parte de ellas, con carreras desarrolladas en los últimos veinte años.

Todas las propuestas tratan de reflejar una visión crítica del mundo del porno, pero al final de cuentas, positiva, es decir, buscan suprimir estereotipos que los vinculan con degeneración, inmoralidad, drogas, promiscuidad, etcétera. De una forma más llana, presentan a todos los involucrados como personas promedio que, en la mayoría de los casos, se muestran orgullosos por su participación en esta industria. 
En particular, los documentales Hot Girls Wanted: Turned on, proponen la existencia de una pornografía alternativa liderada por mujeres y en donde ha disminuido el viejo machismo y violencia de género que caracterizaba a este formato en el último tercio del siglo pasado. Sobresalen los casos de las artistas Suze y Holly Randall, madre e hija respectivamente, dedicadas a la elaboración de fotografías y vídeos de alta calidad (por el uso del vestuario, maquillaje, locaciones e iluminación); así como el caso de Erika Lust, realizadora europea que busca impulsar una propuesta de sexo fuerte, pero con sentimiento, se podría insinuar, que su proyecto cuenta con romance y delicadez. Por otra parte, en el tercer episodio de esta serie documental, se ofrece el caso de la modelo-actriz Bailey Rayne (nombre artístico), destacada como emprendedora, independiente, responsable, que cuida a sus compañeras y segura de sí misma; pero a la vez, es presentada como una adicta al trabajo y peligrosamente cercana al uso descontrolado de bebidas alcohólicas.

Lentamente, se va dibujando el objeto de estudio - el cual se perfila repleto de contradicciones y ambivalencias-, pero antes, hay que ofrecer otro último punto a destacar. Siempre partiendo de los citados trabajos de Hot Girls Wanted y de experiencias personales, se destaca el uso intensivo que las redes sociales (Facebook, Instagram, Whatsapp) están aportando en la construcción de identidades porno. A través de ellas, circula material duro (que más adelante definimos) de fácil difusión entre jóvenes o más específicamente, entre variados públicos carentes de educación sexual básica, repletos de tabúes y con cierto aire de conservadurismo, lo cual torna casi perjudicial el consumo de este material (sobre todo, en una Costa Rica con serios rezagos en materia sexual).

A esto se suma, como es presentado en el segundo episodio de esta serie, titulado "El amor en tiempos de Tinder"3, que los jóvenes están asumiendo de forma natural o idónea prácticas sexuales promiscuas, heteronormativas y con alta exposición a enfermedades de transmisión sexual. ${ }^{4}$ Es decir, están naturalizando los peores aspectos de esta «cultura porno». Más que liberar, este material erótico se convierte en una nueva forma de disciplinamiento corporal, especialmente para las mujeres, convertidas en gratuitas servidoras sexuales de los varones y que deben estar dispuestas a todo; inclusive, se podría considerar que se convierten en un ejemplo operativo del régimen fármaco-pornográfico - el cual fabrica, droga y desecha cuerpos- estudiado por el teórico español Paul Beatriz Preciado (2016). 
Con el objetivo de explicar lo anotado en el párrafo anterior, se partirá de una propuesta dividida en cuatro grandes secciones: las dos primeras anotan los aspectos positivos -aunque muchos lectores podrían disentir de estos argumentos- y luego los perjudiciales de la pornografía; la tercera, ofrece una definición sintética del porno y, la cuarta, intenta -enfatizando en que es una aproximación- profundizar en el tema de las subjetividades que se construyen alrededor de la actriz porno en años recientes. Asimismo, es importante recalcar algunas limitaciones adicionales, tales como el escaso estudio que el tema ha tenido en el contexto costarricense, la imposibilidad de acceder directamente con profesionales del ramo ${ }^{5}$ y más importante, las restricciones [subjetivas y epistemológicas) del autor de estas líneas.

Para resaltar este último aspecto es importante indicar que, como varón «heteronormado», tengo una visión repleta de prejuicios en torno a la pornografía y a lo largo de la investigación he tratado de comprenderlos y, en la medida de lo posible, superarlos.

Igualmente, para elaborar este ensayo se recopiló información proveniente de artículos, sobre todo, de origen estadounidense. Por lo menos, para esta primera entrega, no se tomará como eje central las teorías sexuales que giran alrededor de propuestas de autores como Michel Foucault o Judith Butler, dado que el corpus documental revisado no lo tomó en consideración. Esto se debió a que gran parte de estas teóricas feministas - por ejemplo, Alisa Carse, Consuelo Concepcion, Kate Ellis, Marlene Wasserman, Andrena Zawinski, entre otras- mostraron mayor afinidad al derecho, la filosofía y los problemas inherentes al porno que se generaron en los Estados Unidos a partir de la década de 1960, puntos que en breve serán atendidos. ${ }^{6}$ Asimismo, se tomaron en cuenta textos relativamente viejos (provenientes de la década de 1970), lo cual permitió una visión panorámica e histórica, con trazos del desarrollo teórico de los estudios del porno y sus críticas en los últimos cincuenta años. 


\section{El porno es ineludiblemente «maligno»}

Con solo mirar cualquier escena erótica es más que clara la conclusión de que el porno es perjudicial. En primer lugar, muestra una versión degradante de la mujer, la utiliza como objeto de perversas fantasías sexuales. En segundo lugar, exhibe a la mujer como un ser sucio, con apetito desenfrenado y más importante, rompe su rol tradicional de madre, de virginidad y pureza.

Por ello, la medida más eficaz para combatirlo, es censurar y prohibir todo el material de esta índole, nuestras mujeres no deben ser expuestas a estas vilezas.

En la tradición de estudios de origen estadounidense que se ha revisado, el párrafo anterior sintetiza los principales argumentos que se esgrimen para prohibir el material erótico; como es claro, se tiende a recurrir a las universalizaciones y condenar todo el porno a priori. Resulta llamativo que muchos de estos argumentos fueron (y son) compartidos por agrupaciones denominadas como feministas y por grupos religiosos-fundamentalistas, sobre todo, en el decenio de 1980.

Antes de exponer otras invectivas contra el porno se debe elaborar una breve tipología de éste. El primer caso correspondería a una pornografía erótica-suave (en inglés, muchas veces llamado softcore), donde si bien, se presentan imágenes de sexo explícito, se mantiene un cierto nivel de romanticismo, caricias, placer y hasta éxtasis. El segundo tipo y aquí es dónde se generan las reticencias y sendos debates, es el porno duro (o hardcore), caracterizado por escenas en «extremo explícitas» y carentes de cualquier forma de romance (más adelante se retoma esta discusión). El tercer tipo, ha sido denominado por algunas autoras como thanatica y se refiere a expresiones sexuales donde prima la degradación, la humillación intencionada, los golpes y el dolor. ${ }^{7}$ Igualmente, se podría anotar que la pornografía es indudablemente perversa o perjudicial, cuando muestra y propone la práctica de la violación, tortura, pedofilia y el incesto (Tong, 1982, p. 14).

La mayoría de las críticas contra el porno que se encontraron no establecen estas diferenciaciones y lo consideran maligno sin ambivalencias. A partir de ello, la principal tesis aportada para combatirlo, no necesariamente censurarlo y suprimirlo, radica en que convierte a las mujeres en meros objetos. De esta forma, 
se construyen mujeres irreales, cosificadas y se fantasea con practicar el sexo con meros pedazos de papel o imágenes multimedia, en el caso de vídeos.

A esto se suma, la utilización de las mujeres sin su pleno consentimiento y que el sexo, se convierte en su principal o única razón de ser (Saul, 2006, pp. 45-50).

De aquí se derivan varios problemas anexos. El primero de ellos, es la incapacidad de los hombres para acceder a las mujeres [cosas] mismas, de ahí que recurran a estas fuentes eróticas; aunque si su objetivo es sólo obtener sexo, la cosificación es peor aún. Luego, y esta es una de las ideas más utilizada para combatir el porno, éste siempre será llevado a la práctica, es decir, ver pornografía conduce a practicarla y más precisamente, a tratar a las mujeres como objetos y violarlas, en especial, si tienen la certeza de que el sistema jurídico los exonerará o sus actos no tendrán mayores repercusiones (Zawinski, 1980, p. 8). Es el cliché de que el "porno es la teoría, la violación es la práctica” (Wasserman, 1996, p. 60). Esta violencia del hombre contra la mujer es considerada como una de las marcas propias del porno, es la forma real y culturalmente sancionada en que ven al sexo femenino.

Es importante realizar un breve paréntesis y tomar en consideración que, por esos mismos años, Chandra T. Mohanty criticabaalaacadémicas femenistas porconsiderar a las mujeres - sobre todo a las del Tercer Mundo- como meras víctimas (2008 a , pp. 117-164). Parte de este cuestionamiento también se puede trasladar al contexto de la pornografía, puesto que se ha creado una contraposición entre la mujer moderna culta, fuerte y liberada contra la actriz porno que, “estúpidamente”, entrega su cuerpo a la industria. De nuevo, Mohanty advertía que no se debe apelar a generalizaciones y que al contrario, es necesario tomar en cuenta contextos y particularidades.

Siempre cuestionando el estereotipo de meras víctimas, otras autoras como Heather E. Keith, precisan que si bien estos materiales audiovisuales pueden promover la violencia y hasta extremos como el polémico género snuff (actos sexuales que concluyen con el asesinato de la participante), el origen de dicha violencia también radica en el nivel de racionalidad de los varones, sus creencias religiosas, los grados de simpatía y empatía, en su conjunto, de características histórico-culturales heredadas (Keith, 2001, pp. 123, 125 y 132). 
No obstante, el mayor daño que se supone provoca la pornografía es que amplía el repertorio de posibilidades a los receptores; dicho de una manera simple: los pervierte aún más. En consecuencia, modela comportamientos, reduce-suprime la empatía y, el mayor riesgo, es que los niños y jóvenes están siendo formados por una peligrosa combinación de porno-terror que desencadenaría en peores arremetidas contra las mujeres.

A partir de aquí, las subsecuentes críticas se tornan más endebles. Una de ellas estriba en la defensa religiosa y de grupos que afirman escuchar la consciencia moral de la sociedad. Ejemplo de ello, son las palabras del papa Juan Pablo II, quien consideraba que la mujer no debía ser un objeto sexual lujurioso (Heartney, 1991, p. 18). Tras condenar la pornografía, también despreciaba a la prostitución, el aborto, las píldoras anti-conceptivas, el hedonismo y las expresiones variadas de lujuria femenina. ${ }^{8}$ Además, tanto las iglesias cristianas como los grupos moralistas rechazan estas expresiones eróticas y las emplean como un pilar para mantener la opresión y posición subordinada de las mujeres, ya que la explotación del porno se termina homologando con el aborto y más importante, ambas prácticas son perniciosas, puesto que la mujer, como sujeto universal, tiene el deber «naturalizado» de salvaguardar la vida, la maternidad y la moral misma.

Prohibir el porno, censurarlo en los Estados Unidos, en el grueso de Occidente y hasta en Latinoamérica, tiene en parte, un trasfondo de considerar que el sexo extra-marital es sinónimo de embarazos no deseados, violación, vergüenza, nada más. De este modo, el cuerpo femenino es definido como pasivo y acechado por la hipersexualidad masculina, de ahí la necesidad de ser protegidas por el sacramento matrimonial y la familia nuclear. ${ }^{9}$

En otros casos, se acepta que la pornografía presenta una pequeña ventaja o uso positivo: permite la catarsis en los consumidores varones. Es un salvoconducto de sus peores fantasías sexuales y con ello, se evitan comportamientos más dañinos. El nuevo problema de fondo es que los hombres necesiten de esta purga en primer lugar (Garry, 1978, pp. 395 y 401). Al requerirla, significa que deshumanizan a las mujeres, las rebajan de su posición de «santas». Asimismo, dado que este arte perverso erótico es en extremo didáctico, se están sexualizando las inequidades, las jerarquías que rebajan a las féminas y lo peor, el efecto es inicialmente indirecto, 
pero acumulativo, a largo plazo, en el hombre crecerá la misoginia y sus instintos [¿latentes?] de violador (Carse, 1995, pp. 157-67).

Por último, el material erótico también se considera como habitual en hombres con serias limitaciones sociales, especialmente, en aquellos carentes de éxito laboral y cuya personalidad masculina se encuentra en condiciones de extrema fragilidad. Para ellos, el porno y la imagen del macho conquistador son los últimos bastiones ante la pérdida de sus identidades esencialistas. En esta misma línea, el porno también es visto como plano, aburrido, como meros objetos apilables sin valor alguno y que lo transmitido por sobre todas las cosas, es la desesperación de las chicas que exhiben (Heather Sellers, 2009, pp. 32 y 37).

\section{3. ¿Y si el porno fuera la mejor profesión del mundo?}

Algunos autores afirman que todos los seres humanos anhelamos ser vistos, otros lo traducen en que buscamos el cariño, el placer, ser amados. Por eso, muchos optan por una carrera en la pornografía; además, dedicarse varios años a recibir y dar placer, a compartir deseos y cuerpos con otras personas, podría ser una excelente profesión... Las defensas de la pornografía han demostrado ser más curiosas que las sendas críticas expuestas con anterioridad. Una de las principales se enmarca en los derechos y libertades defendidos por la Modernidad, el simple privilegio de escoger el material más obsceno y repugnante disponible (Heartney, 1991, p. 19).

En consecuencia, la censura es una muestra de la falta de confianza de una sociedad en sí misma y es, por mucho, una marca propia del autoritarismo (Dyal, 1976, p. 97). Precisamente, para entender e inclusive, promover el porno, debe partirse de una discusión en torno al tema de la obscenidad esgrimido como uno de los principales motivos para prohibirlo. ¿Qué es obsceno? ¿La exposición de clítoris, vaginas, penes, anos, etcétera? ¿Coitos, eyaculaciones, fluidos, cuerpos sudorosos? Cuando el porno es acusado de grotesco, anti-natural y maligno, no se están expresando argumentos objetivos, sino, meros juicios de valor. 
Igual, cuando en muchos contextos se defiende una mítica moral, no se están apelando a valores universales, al contrario, son las creencias, estereotipos y demás representaciones sociales de unos pocos, tratando de ser impuestas al grueso de la sociedad. Consecuentemente, el porno es obsceno y censurable, sobre todo, cuando confronta a los estándares vigentes de una comunidad; por ejemplo, en un pueblo homofóbico, cualquier expresión erótica con dos mujeres u hombres será considerado como dañino y no se le reconocerá ningún valor social, literario, artístico, político o científico. El resultado no se reduce a la mera censura, sino que radica en la supresión de la libertad de expresión y peor aún, en una peligrosa complacencia moral.

A partir de esto, se pueden inferir nociones que contradicen las críticas al material erótico. Si lo bizarro, prohibido o supuestamente degradante, genera amplio placer y excitación, no puede ser considerado como disparador automático de la violación (Ellis, O’ Dair y Tallmer. 1990, p. 17). Al contrario, Robert A. Dyal afirma que el porno es una sana catarsis, ayuda a suprimir inhibiciones, es un vehículo de instrucción en material sexual y un pleno acceso libre, reduce los crímenes en este campo. Inclusive, mientras el peor porno (legal, claro) brinda gratificaciones fáciles, el más alto o elaborado, equivale a poesía moral y de la mente, provocando un estado extremo de consciencia y un profundo éxtasis; ya que la sexualidad, en todas sus sanas expresiones, es una parte ineludible del ser (1976, pp. 110-115).

Para concluir esta sección, es necesario citar otro de los puntos fuertes de la pornografía. Primero, estas exhibiciones de sexo muestran los otros apetitos que la Modernidad ha tratado de ocultar y perseguir.

Esta es una posición ambivalente, ya que mientras el sexo-ocio es condenado, el sexo-reproductivo ha sido apoyado, puesto que es un pilar del sistema económico capitalista: la reproducción perpetua de la mano de obra a través de la explotación de las mujeres; pero, que ellas disfruten plenamente del coito y controlen a plenitud sus cuerpos, es una grave amenaza al statu quo (Federici, 2013, pp. 174-176). Segundo, el mismo patriarcado busca mantener el monopolio del deleite sexual en manos (o en el pene) de los varones, mientras la mujer es reducida a un rol pasivo y hasta se le imposibilita hablar libremente de temas sexuales (Ellis, O' Dair y Tallmer, 1990, p. 16). Tercero y último punto, se puede mencionar la posición de la veterana actriz porno Nina Hartley, quien afirma que se debe disfrutar del sexo 
como una actividad satisfactoria y sin culpas, enfatizando en que las mujeres tienen un protagonismo central y no deben ser caracterizadas como neuróticas, infelices o incompletas (Wasserman, 1996, p. 61). Por eso, el porno/lo erótico puede desarmar la ignorancia y guiar hacia sexualidades diversas, trasgrediendo las prohibiciones imperantes, como afirma Consuelo M. Concepción, el porno puede dar mayor expresividad y propiciar igente más inteligente! (Keith, 2001, p. 100).

Para cerrar este apartado, podríamos sintetizar algunos aspectos positivos de la pornografía de una forma esquemática:

a) El derecho a desnudarse y practicar relaciones sexuales frente a las cámaras como parte de las libertades defendidas por los sistemas democráticos modernos.

b) Los estándares morales o de «obscenidad» son construcciones sociohistóricas que cambian a través del tiempo y el espacio; no son esenciales y mucho menos, universales. Por ende, un acto sexual determinado no debe ser catalogado a priori como obsceno.

c) El porno puede constituirse en una catarsis, libera el placer o, visto desde otra perspectiva y en sintonía con el posporno, equivale a pedagogías sexuales de lo «perverso».

d) El material pornográfico demuestra que el sexo (y el orgasmo) desborda los mecanismos normativos, especialmente, aquellos que lo restringen al terreno de la reproducción, el patriarcado y la heteronorma.

\section{Una propuesta para definir la pornografía}

Antes de proponer una definición sintética y claramente subjetiva de pornografía, es importante anotar que, en el grueso de textos consultados, se carece de una verdadera genealogía del concepto y de una contextualización histórica del mismo. Por supuesto, dadas las limitaciones del presente ensayo, sólo se ofrecen unos breves elementos referenciales. En el sentido etimológico, la palabra pornografía quiere decir "la escritura de las prostitutas" y su origen se remonta al mundo grecorromano, especialmente visible en los dibujos eróticos de la antigua ciudad 
de Pompeya (Tong, 1982, p. 2). A lo largo de la historia y dependiendo de la región -América Antigua, África, Asia- las expresiones sexuales en esculturas, literatura y pinturashansidoincontables, constantes, popularesy, enmuchoscasos, escandalosas.

Es importante realizar un contraste con el caso europeo occidental, puesto que muestra mayor tolerancia hacia la pornografía y su uso es de larga data, aunque no desprovisto de contradicciones. En el siglo XVIII, en plena Ilustración, el porno se fusionaba con la filosofía, de esta forma, se elaboraron discursos explícitos que despertaban los deseos sexuales y de paso, se evadía la censura. Por otra parte, era un material ambivalente, puesto que defendía la sexualidad reproductora y a la vez, abogaba por la excitación sin frenos. Interesante revisar el caso de escenas homoeróticas - tanto de hombres como de mujeres-, en los diálogos se les condenaba, pero explícitamente se remozaban en su práctica. En última instancia, el porno se tornó pansexual, todo goce era permitido y los tabúes fueron trasgredidos sin empachos (Clark, 2010, pp. 231 y 254).

Ya entrado el siglo XIX a la pornografía se le reconocía su valor didáctico, desde varias décadas atrás, los franceses pudieron aprender a través de ella, el denominado método de la marcha atrás (salir de la vagina y evitar la eyaculación). ${ }^{10}$

Mientras que en la Inglaterra victoriana (1840-1900), los hombres acomodados podían ser avergonzados si se descubría que utilizaban prostitutas o eran aficionados a la literatura pornográfica, más allá de un leve escándalo, su posición social se mantenía intacta.

Más que precisar cada momento en su desarrollo, se puede destacar que la pornografía contemporánea tiene un momento de quiebre definitivo en el siglo XIX con la aparición de la fotografía y más tarde, con la cinematografía. En sus inicios, ambas fueron cuestionadas por su falta de inclinación artística y fueron catalogadas como meros oficios. ${ }^{11}$ En ese contexto, el porno moderno se traficó como fotogramas de escasa circulación dadas las limitaciones y elevados costos de las materias primas; inclusive, en la Inglaterra de 1853, ya habían sido prohibidos este tipo de productos eróticos (Wasserman, 1996, p. 58). Ya entrado el siglo XX y con el abaratamiento de los costos, sumado a la aparición de las publicaciones periódicas, especialmente con las revistas en los Estados Unidos -las célebres 
Playboy (1953), Penthouse (1965) y Hustler (1974)- se propició su distribución masiva. Esto no eximió que se le persiguiera para evitar que corrompiera a la juventud, como fue el caso de la Francia de gaullista en las décadas de 1950 y 1960.

Mientras que en los últimos veinte años la expansión de los medios digitales, el internet y las subsecuentes redes sociales, han permitido el desarrollo de formatos más portátiles y de fácil acceso; de ninguna forma, esto puede considerarse como una victoria y menos, como un triunfo de los derechos sexuales, tal vez, ha sido lo contrario. A finales de los años sesenta del siglo pasado, al temor de la "Revolución Sexual", los gobiernos occidentales comenzaron a suprimir restricciones al material pornográfico con el objetivo de neutralizar o reducir las demandas de verdadera libertad sexual. En consecuencia, se elevó el consumismo y los afiches o vallas cargados de mensajes e imágenes sexuales («no duras») se han tornado omnipresentes (Clark, 2010, pp. 469-470).

Un último punto a destacar es que el porno ha sido devorado por el consumismo sexual, siendo privado de gran parte de su capacidad trasgresora (como aparentemente la tuvo en otros momentos) hoy se utiliza para reprimir y crear productos controlados (o nichos de mercado) y, a la vez, se le acusa de alentar a las mujeres a ofrecer a los hombres "nuevos servicios" como el sexo oral y anal, o de que los hombres recurran con más tranquilidad a las prostitutas. ${ }^{12}$

Dejando de lado este breve repaso histórico se tratará de proponer una definición. Muchas obras de literatura han sido más explícitas y detalladas que el material pornográfico contemporáneo (fotos o vídeos), no obstante, la principal característica es su visibilidad y que, supuestamente, ¡no deja nada a la imaginación! Por supuesto, esto es debatible y como bien anotó Camilo Retana, una de sus principales claves, es que todo material erótico depende en gran medida, de la forma en que se le observa, la mirada cómplice. ${ }^{13}$ Marlene Wasserman coincide en esta postura y agrega, con suma claridad, que la imaginación es la que se podría considerar como pornográfica, no la imagen en sí.

Además, la censura y repudio contra estos materiales va de la mano con construir un cordón imaginario que aísle el sexo y lo coloque fuera del resto de nuestras vidas. Siempre siguiendo la ruta trazada por Wasserman, sin porno, se carece de 
imágenes de referencia que precisamente fomenten la creatividad sexual. Con ello, las mujeres en particular, son obligadas a repetir un sexo bajo los estrictos cánones del matrimonio heteronormativo, reproductivo y peor aún, aburrido (Wasserman, 1996, pp. 59-62).

En lo personal y retomando a los autores consultados, se considera que el porno o los materiales eróticos ${ }^{14}$ son una posibilidad de libertad sexual, una forma de expresión artística que cuenta con una estética sofisticada y más importante, es una grabación imaginativa de la voluntad sexual humana (Dyal, 1976, p. 110). A esto se debe complementar que, el porno es una serie de textos y materiales que excitan al espectador y trasciende dicho acto, puesto que trasgrede los tabúes dominantes sobre el cuerpo y la sexualidad (Cortiel, 2005, pp. 115).

Líneas atrás se insinuó que la erótica puede ser considerada como arte, ya que utiliza escenarios altamente elaborados, maquillaje, iluminación, sólo para citar algunos elementos. Del mismo modo, aunque se muestre con sumo detalle genitales, actos sexuales íntimos y placer; ello no equivale a obscenidad. A esto se agrega que, hombres y mujeres de cualquier procedencia y sin importar sus tipos de cuerpos quieran mostrarse orgullosamente desnudos, desinhibidos y voluntariamente practicar el coito (aunque medie una paga), lo cual no se torna en algo condenable y tampoco aberrante (Rea, 2001, pp. 121-132).

Para este punto, el estimable lector y lectora deberá perdonarme, esta es una definición casi utópica, busca que el porno sea desestigmatizado, pero no se niegan sus claras falencias. Las formas más tradicionales y comerciales de materiales sexuales no suelen tomar en consideración las fantasías de las mujeres (menospreciando su diversidad de placeres), más aun, se esmeran en la reproducción de géneros y categorizaciones, no sólo centrándose en el hombre y la mujer, sino en los nichos: porno gay, lésbico, bisexual, transexual, sadomasoquista, fetichista, entre otros. Asimismo, el modelo estándar es indudablemente heteronormativo, "caucásico", reduce el placer a la mera penetración (sumando el protagonismo de irreales falos tamaño titán) y otros clichés que en el siguiente apartado se discutirán. 


\section{Las tenues subjetividades en el porno}

Ya para este punto, es evidente y necesario apuntar que el porno contemporáneo busca imprimir subjetividades tanto en sus intérpretes [femeninas] como en sus espectadores. Crea mensajes contradictorios que se hilvanan entre la liberación sexual y nuevas formas de represión, es por mucho, un discurso y puesta en escena sumamente ambivalente.

Ahora, es preciso enfatizar que, hasta el momento, este trabajo ha sido demasiado benigno e idealista con respecto al mundo pornográfico. En los siguientes párrafos, se tratará de plantear una visión más crítica que refleje otras principales preocupaciones. Tras consultar diversos textos sobre la temática, asomaron varias limitaciones, la principal de ellas, es que las investigaciones desde la década de 1970 carecen de una discusión profunda del tema de género y sólo se limitan a una perspectiva un tanto maniquea acerca de las bondades o perversidades del porno, sumando la dicotomía legal/censurable o tolerar/prohibir.

Tres son las mayores falencias que se deben abordar o tratar de discutir: a) las imágenes tradicionales de sexo normativo que imperan, b) la mercantilización de los cuerpos y c) los personajes femeninos que se han desarrollado; por supuesto, estos elementos se encuentran estrechamente vinculados.

Entonces, el porno a pesar de suspretensionesmáximasy superando la meraacusación de cosificación, se limita a reproducir patrones claramente heteronormativos, en los cuales, la mujer es pasiva-receptiva y el hombre agresivo-penetrante (Whisnant y Mantilla, 2007, p. 60). Dejando de lado apreciaciones limitadas a la obscenidad, las imágenes que se muestran habitualmente buscan impulsar el sexo reproductivo con mujeres insaciables y hombres con penes gigantes que siempre podrán generar erecciones y semen; el discurso que se maneja refiere a un ser humano máquina sexual, siempre lista para el acto carnal. Aunque muchos teóricos afirman que el porno promueve el placer, ciertas sutilezas en su montaje dan paso a cuestionarlo, ya que las parejas no suelen emplear métodos anti-conceptivos, el condón es un gran tabú raramente utilizado y más que las eyaculaciones en el rostro, el máximo

premio es una en la vagina, ${ }^{15}$ insinuando al espectador que no debe preocuparse por enfermedades de transmisión sexual y tampoco por el embarazo. 
El impulso reproductivo no es el único mensaje que se defiende, también y con mayor fuerza, los roles esencialistas de la mujer. Gran parte de la crítica contra el porno se ha centrado en defender la imagen femenina [y heteronormada] de pureza, delicadez y fragilidad; mantenerlas en el pedestal como madres o catequistas, mientras que «las caídas» no merecen respeto (Garry, 1978, pp. 395-421). Por supuesto, no vamos a favorecer los argumentos moralistas y conservadores, no obstante, consideramos que el porno contemporáneo los apoya. Veamos las absurdas jerarquías de erótica y pornografía, enmarcados en casos como Playboy y Hustler, respectivamente. El primero era «más suave» ${ }^{16}$, porque presentaba mujeres no tan malas, que se desnudaban y exponían con mayor detalle los senos y una insinuación de la vulva y los labios mayores, pero nada más. Mientras que el porno-Hustler, muestra a mujeres exhibiendo con sumo detalle el clítoris y la vagina.

Claro, esta distinción es algo conocida, sin embargo, en este estudio es utilizada como aspecto preliminar para desarrollar el argumento, ya que en esta lógica porno-patriarcal, la mujer en medios eróticos ligeros aún no ha perdido toda su santidad, se encuentra lejos de la cúspide de su decadencia. Hemos denominado como porno-consagración el final de una «transición y aprendizaje» que la modelo porno femenina debe tomar: inicia con imágenes en solitario de su cuerpo desnudo, aumentando paulatinamente el nivel de exhibición, luego agrega el uso de juguetes como dildos, seguidamente practica sexo lésbico y por último, se consagra con la penetración masculina. ${ }^{17}$ Este proceso no es universal, muchas lo siguen debido a que cada escalón depara una paga diferenciada y más elevada, cifrada en miles de dólares por escena, especialmente si ésta es más «dura». Una vez superado el límite del contacto fálico, la actriz puede abrazar formas de sexo que la misma industria insinúa y publicita como de mayor decadencia: orgías, interracial, múltiples penetraciones y fetiches varios.

El eje central sobre el cual se quiere llamar la atención, es que se reproduce un discurso conservador y heterosexista que declara a la penetración como una pérdida irreparable de la dignidad femenina, por lo que la intérprete adquiere un nivel de mayor perversión o atrevimiento. Esto también se ve reflejado en el idioma, con palabras tales como "fuck", "screw" en inglés o coger, atornillar, sodomizar en el castellano; son insinuaciones de violación y de pérdida de la virginidad. Entonces, se declara implícitamente que son «mujeres malas» que han caído con el pene y sólo les resta, caer más bajo. 
Páginas atrás, se discutía un poco acerca de la objetivización de las mujeres, es necesario precisar que esto no equivale a coincidir del todo con dicho argumento. Primero, porque lo anterior se debería aplicar a todos los participantes en el mundo del porno, no sólo las mujeres, sino también a los varones, travestís e intersexuales. Segundo, el proceso es más complejo y se ubica en una peligrosa mercantilización sexual. Es necesario reiterar que aquí se aboga por un sexo libre y se respeta plenamente que cualquier persona tome la decisión de participar en esta industria y entable relaciones con quien le plazca frente a una cámara. Aunque, no es lo mismo que la pornificación del libre mercado la mera venta de cuerpos. El tema es más complejo de lo que este párrafo puede contener y es necesario obtener datos que indiquen la procedencia de los intérpretes, sus motivaciones, el tiempo medio en que participan en el porno e inclusive, su vida después de tal carrera, entre otros referentes.

Silvia Federici ha insistido - y con suma razón- que la Modernidad capitalista se ha esmerado en nuevas formas para la venta del cuerpo, sobre todo del femenino, aparte de la maternidad subrogada, la prostitución o la venta de órganos, el porno también se ajusta a estos parámetros. Sería ingenuo suponer que todas las jóvenes [marginadas] que son reclutadas en estas filmaciones -especialmente aquellas con escasa experiencia sexual, barreras idiomáticas y demás desventajas- accedan sin contemplaciones a participar en empresas cuyos riesgos son elevados; sumando el problema de una sociedad conservadora y mojigata que las expondrá a una elevada tensión psico-emocional.

De esta forma, la pornografía puede mercantilizar con mecanismos sutiles, reafirmando, como señala Federici, el uso de la libre voluntad: se acepta la propaganda del mercado y se ingresa voluntariamente al porno, la mujer puede ser golpeada, escupida, humillada, pero ella está en control; en todo caso la cosificación es voluntaria y su espíritu es feminista, el sistema capitalista absorbe una lucha en su contra y la resignifica para su beneficio (Whisnant y Mantilla. 2007, pp. 60-61).

Esto nos lleva a retomar parte de la pregunta inicial, ¿quién es la actriz porno? Muchas revistas y vídeos incluyen una pequeña nota de advertencia que generalmente pasa desapercibida, textualmente, dice así: “Todas las fotos corresponden a modelos profesionales, excepto en casos anotados. Las fotos ni los textos descriptivos de las mismas, representan la conducta actual de la modelo, sus declaraciones o 
personalidad."18 A partir de esta aclaración por parte de la industria, se podría inferir que las modelos son meras intérpretes y que la sexualidad expresada en estos formatos multimedia no refleja más que su selección temporal de profesión; son actrices, nada más.

Aunado a esto, los textos que acompañan a las fotografías, sobre todo las del afiche central de las revistas (centerfold en inglés), incluyen fichas biográficas que se esmeran en presentar a las chicas como mujeres perfectamente «normales», con amplias aspiraciones, no sólo el viejo cliché de querer triunfar en Hollywood, sino que se extiende a un amplio abanico de posibilidades laborales (médicas, bailarinas, agentes de bienes raíces...), sumando los detalles acerca de sus pasatiempos, deportes, películas y series de televisión favoritas. En algunos casos, se les muestra como sujetas hipersexualizadas, "curiosas" (ciertas afinidades al lesbianismo), pero en última instancia, siempre heterosexuales. Con ello, el mensaje implícito es: son máquinas del placer, tienen amplios poderes eróticos, pero regresarán al santuario del hogar para cumplir sus funciones de esposas y madres. Sin duda, son actrices y modelos, no obstante, su interpretación no es de liberación sexual, sino de la reproducción de roles y estereotipos de género.

La actriz porno, se mueve en esta peculiar frontera: es una profesional, una fantasía y también representa estos vicios no superados del sexismo y el patriarcado. A esto se suma, las claves en que generalmente se le representa en filmes y sesiones de fotografías: a) es una mujer deseada y visiblemente satisfecha, b) suele enfrentarse a un pene duro y enorme (y siempre lo doblega), c) es frecuente que se le represente con múltiples varones, demostrando su gran resistencia sexual, capaz de satisfacer a varios simultáneamente (Wasserman, 1996: 63). De estas características excesivamente generalizadas y de una visión anacrónica (anclada en los debates de la década de 1970) se ha concluido que en el porno predominan las mujeres jóvenes, desesperadas en términos económicos, que cuentan con pésimas condiciones laborales, sujetas a coerción y abusos, carentes de credibilidad social e impotentes ante sus abusadores (Carse, 1995, p. 177).

En este punto, quisiéramos llamar la atención sobre varios aspectos que limitan el estudio de la pornografía. El primero de ellos es que muchas discusiones se han congelado en el contexto de los decenios de 1960 y 1970, cuando estos materiales 
eran casi ilegales, subterráneos y estigmatizados como criminales, enfatizando en el abuso que sufrían las mujeres. El objetivo no es contradecir estos puntos, sino llamar la atención sobre la necesidad de historizar este proceso y recopilar relatos de las intérpretes de esa época [como auto-crítica: es necesario localizar y acceder a esos estudios]. Un segundo punto medular es que el género y el porno, han tenido una relación un tanto fría. Nótese con suma claridad que a lo largo de este ensayo hemos manejado las categorías dicotómicas que Judith Butler y otras autoras tanto han cuestionado, como hombre/mujer, hetero/homo, santa/puta, etcétera. (Butler, 2007, p. 24). ). Partiendo sólo de este punto, se puede reiterar el papel fundamental que el porno desempeña naturalizando estos roles y sustentando el statu quo. Entonces, en el porno no se ofrecen cuerpos en busca de los placeres más exquisitos, sino identidades esencialistas que no logran trasgredir los límites anclados en el mundo real; más que fantasías, concuerdo con Camilo Retana al cuestionar que el porno termina por encadenar y reprimir la expresión de sexualidades libres y sin clasificaciones.

Veamos otro ejemplo. Aprovechando el concepto de interseccionalidad de Crenshaw, la pornografía también puede ser considerada como racista y clasista (1993, pp. 1241-1299).En una muestra promedio de vídeos o fotografías, ${ }^{19}$ el acto sexual va a tener lugar entre una pareja -sin importar la orientación sexualgeneralmente "blanca", de clase media, con profesiones comunes y que cuentan con automóvil y casa propia. Brillan por su ausencia los problemas cotidianos de la mayoría de las personas en términos de relaciones sexuales: salud (libres de enfermedades de transmisión sexual), espacio, tiempo, agotamiento físico, horario laboral, cuidar a los niños, entre otros. Insinuando a su vez, las máximas del libre mercado: sexo para todos... ¡aquellos que cuenten con los recursos económicos propios de la clase media y alta!

En el trasfondo, lo que se busca cuestionar es que el porno no debe ser analizado partiendo únicamente del análisis de la mujer o el feminismo, debe ampliar y establecer intersecciones con temas de género, raza y clase. De esta forma, la pornografía ¿es sólo dañina para la mujer participante? Los varones generalmente son expuestos a largas sesiones en las que deben mantener la erección y las miradas de aprobación o disgusto de los equipos de filmación, sumado a que un pobre desempeño, implica la acusación de rechazar a súper modelos femeninas 
(consideradas por la estética dominante como «perfectas») y que para ganar un sitio en la industria deben recurrir a píldoras u otros dispositivos de agrandamiento fálico e inclusive, recurrir a prácticas homoeróticas para sostener sus carreras. ${ }^{20}$

En el tema de raza se puede empezar señalando lo más obvio: el grueso de pornografía corresponde a rubias caucásicas, las empresas con intérpretes pertenecientes a otras etnias son de tipo nicho o para públicos especializados.

Retomando lo señalado líneas atrás, uno de los mayores atrevimientos (o incluso, riesgos) de una modelo, es entablar sexo interracial, sobre todo con afrodescendientes. Una variante sexual sumamente polémica y provocativa en el contexto de los Estados Unidos y Europa, que permite observar como los viejos estereotipos del racismo gozan de una peligrosa vitalidad, sobre todo en temas sexuales, dónde son homologados con el bestialismo. ${ }^{21}$

En cuanto a la clase, si bien el porno se ha abaratado, sería ingenuo suponer que es un mero entretenimiento al alcance de todos los estratos sociales. Es claro que las redes sociales han favorecido su difusión, aunque los precios de los materiales son notorios y se requieren de tarjetas de crédito o débito para crear cuentas en los principales sitios, equipos electrónicos acordes, incluyendo dispositivos de almacenamiento y conexiones a internet veloces, sobre todo, para la proyección de vídeos de alta resolución. En otros aspectos socioeconómicos, es importante enfatizar que el porno se encuentra en la vigorosa tarea de crear post-cuerpos. ${ }^{22}$

Aparte de los varones absurdamente dotados, las mujeres pueden ser perfeccionadas o convertidas en caricaturas del cuerpo humano, a través de la cirugía estética, los implantes de cualquier pieza necesaria, los estrictos regímenes nutricionales y de gimnasio. Es otro mensaje fuerte de la industria: si deseas una mujer o un varón como los mostrados en la pantalla, debes buscar reformatear por completo tu cuerpo para alcanzar su nivel de potencia sexual, para ello, se puede recurrir a la tecnología (los infladores de pene) o la medicina más avanzada. 


\section{Conclusiones}

Es claro que definir a una actriz pornográfica a priori es un grave error, más bien equivale a encasillarla dentro de algún sistema de poder categorizante.

La intérprete que hemos tratado de deconstruir es un universo de posibilidades, un ser al que nunca se podrá acercar por completo. Por eso, es claro que ellas se encuentran en un complejo juego de performatividades donde son, simultáneamente, diosas encarnadas del sexo, muchachas que ocupan pagar sus cuentas, enfrascadas en una simple profesión o fueron coaccionadas a participar en este mundo. La misma industria, se torna ambigua con sus personajes, trata de presentarlas como sujetas auténticas, dinamita erótica y luego, de nuevo, las normaliza, recordando que en el fondo son dulces jóvenes o damas, prestas a la maternidad y el matrimonio. Entonces, tal vez sean meros cuerpos que están de paso frente a las cámaras, prestan su energía por un lapso de tiempo variable para seguir con sus vidas regulares ¿una industria que las usa y las desecha?

Precisamente me ha quedado claro que con la pornografía no pueden existir verdades o conclusiones absolutas. Es un universo que no sólo está vinculado a múltiples interpretaciones, sino, que cada caso o persona involucrada presenta sus propias particularidades. Lo anterior no exime de entender y cuestionar algunos aspectos globales. Uno de ellos y probablemente el principal, es que las verdaderas subjetividades que se están construyendo se encuentran en los discursos que la industria porno o más bien, la mercantilización sexual del neoliberalismo hegemónico transmite y quiere que se consuman acríticamente. La pornografía utópica ofrece la posibilidad de imaginar un pansexismo, una entrega pura y sin represiones al goce de los cuerpos y los deseos; insistiendo en una plena liberación con respecto a falsos cánones morales o corporales. Sin embargo, no se puede olvidar que estamos muy lejos de alcanzar ese grado de libertad y desarrollo erótico, al contrario. Nos encontramos en una sociedad que se ha ensañado de nuevo con reprimir a las mujeres, con nuevos fundamentalismos renovados y sedientos de sangre, con masculinidades aún más retrógradas, sólo para citar los ejemplos más chocantes de la actualidad (Mohanty, 2008b, pp. 407-464). Lamentablemente, estamos muy lejos de ese paraíso sexual. 
Es evidente que podemos superar los añejos debates en torno a un porno bueno o malo, por supuesto que las violaciones, incesto y violencia gratuita son perjudiciales, pero eso no lo consideramos pornografía, ni mucho menos erotismo; es mero "gore”, horror humano llevado al extremo.

El porno que defienden muchos autores y autoras, se refiere a la sexualidad exponencial, al grado de ser arte, liberación de los sentidos, de sus pulsaciones de placer más escondidas o que ni siquiera se creía que existieran. Es un aluvión de sensaciones corporales y psíquicas, precisamente, es regresar a la unión cuerpo y mente que la Modernidad se ha empecinado en negar. Esa es la pornografía anarquista y subversiva que desearíamos que se logre consolidar, aquella que no usa ni desecha cuerpos, que más bien, celebre las proezas del poder sexual.

Un erotismo no reproductivo, ajeno a la promiscuidad sin sentido, responsable, de empatía, preocupado siempre por el bienestar y el disfrute de la pareja; ese es el nuevo orden sexual, con el cual, por lo menos, nos podemos contentar con fantasear.

\section{Notas}

${ }^{1}$ Entendiendo subjetividades como la formación del sujeto, el proceso inacabado -fluido- de ser. El sujeto recargado de contradicciones, ambivalencias, anhelos, necesidades físicas e imaginarias, pulsaciones, etcétera.

${ }^{2}$ Todos estos proyectos documentales se encuentran disponibles en la plataforma de streaming, Netflix. En la sección de material consultado, se agregan los detalles de producción respectivos.

${ }^{3}$ Es una aplicación para teléfonos inteligentes y dispositivos similares que permite revisar un inventario de fotografías de personas disponibles, ya sea para entablar relaciones de amistad o románticas, sobre todo, contactos rápidos o inclusive, efímeros.

${ }^{4}$ Debe advertirse que esta propuesta no busca ser «moralista», consumir porno no lo consideramos como malo; no obstante, prácticas sexuales irresponsables y 
que reproduzcan la sujeción de la mujer, son más que perjudiciales. En el citado documental, la transmisión de material porno y sobre todo, los valores propios del patriarcado contemporáneo, incitan a las jóvenes a entregarse sexualmente sin que medien sentimientos (tema que más adelante abordamos) y exhibirse como meros objetos; todo esto, es lo que buscamos estudiar.

${ }^{5}$ Aunque en Costa Rica se han desarrollado algunas producciones, sobre todo películas y efímeras revistas/periódicos, de momento no tenemos contacto con sus realizadores o acceso a dichos productos.

${ }^{6}$ Aparte de las autoras previamente citadas y cuya referencia se encuentra en el apartado de bibliografía, se partió de referentes teóricos afines a Judith Butler, especialmente la performatividad, por ejemplo, como el género [femenino] es representado y ritualizado cotidianamente, sin menospreciar las resistencias y trasgresiones que se generan; en este caso en particular, enfocados en el ambiente del porno. Asimismo, el texto se acerca [tímidamente] a las propuestas del posporno que consideran que el cuerpo y la «obscenidad» son un arte que no debe ser mercantilizado; estas mismas "pedagogías" deben ayudar a liberar sexualidades u otorgarles nuevos espacios o inspiraciones para el deleite sexual; este sería un "porno idealizado". Para más detalles se puede consultar: Magaña, 2018, pp. 190-192.

7 Tong, la autora original de estas ideas, también está consciente de que hay formas de sexualidad donde se vincula el dolor y el placer, afines al sadomasoquismo, pero el concepto de thanatica, se refiere específicamente a provocar sufrimiento en los demás, sin consentimiento (Tong, 1982, p. 3).

${ }^{8}$ Otra crítica subyacente al porno, es que por su mera lujuria, es condenable. El sexo sólo se concibe como gentil y amoroso (Concepcion, 1999, p. 98).

${ }^{9}$ Mujeres encasilladas en la pasividad erótica, el amor romántico y la fidelidad, pero sin goce real (Fernández, 2009, p. 67).

${ }^{10}$ La autora también precisa que el porno es probablemente, uno de los principales impulsores de la práctica del sexo anal entre parejas heterosexuales; lo ha puesto de "moda"(Clark, 2010, p. 249). 
${ }^{11}$ Por supuesto, la fotografía y el cine obtendrían laureles artísticos, el cine en particular se le consideraría, integrador, pues da cabida a la música, la arquitectura, la danza, etcétera (Debray, 1994, pp. 223-224).

${ }^{12}$ Es preciso aclarar que no se está en contra de dichas prácticas sexuales, sino en que se promuevan como obligaciones dentro de las parejas, toda expresión erótica debe provenir del mutuo consentimiento. Clark, 2010, pp. 491-492).

${ }^{13}$ Aunque Retana propone que el porno se limita sólo al placer visual, el resto de los sentidos y del cuerpo, son excluidos; aunque no compartimos esta postura, aceptamos el predominio de la mirada, no así su tiranía (Camilo Retana, 2008, p. 51).

${ }^{14}$ No queremos hacer distinción tajante entre ellos, pues como ya se anotó, las diferencias se sitúan más en el campo de los juicios de valor, los endebles estándares morales y la variable definición que cada quien presente de "obscenidad".

${ }^{15}$ La eyaculación en el rostro, en el idioma inglés es conocida como el money shot, es una forma de lograr un clímax visible, sobre todo de la escena. Aunque, un cumpie o eyaculación en el área vaginal es mejor pagado, ya que muchas actrices lo rechazan al elevar el riesgo de embarazos o de contraer enfermedades venéreas (Surnow, 2016).

${ }^{16}$ Material ligero (softcore) o porno-artístico, también se encuentra en empresas y sitios como: hollyrandall.com, suzenet.com y metart.com.

${ }^{17}$ El proceso no es universal, muchas jóvenes empiezan sus carreras con escenas de sexo duro, es decir con uno o varios varones a la vez; especialmente las originarias de Europa del Este, dado que sus condiciones de marginalidad las orilla a tratar de obtener mayor dinero en poco tiempo. Por ejemplo, las intérpretes femeninas que realicen escenas con mujeres y hombres, pueden ganar entre 300 a 1.500 dólares (por escena), sólo con mujeres, un rango de 700-1200 dólares; mientras que el actor promedio obtiene un rango entre 500 y 1.500 dólares por escena (Morris, 2016).

${ }^{18}$ La traducción es propia (Hustler, 1999, p. 4). 
${ }^{19}$ La cual se puede encontrar en una búsqueda casual o un acceso rápido en sitios como pornhub.com o xvideos.com.

${ }^{20}$ Por cuestiones de conocimiento y revisión teórica, el tema de los varones en el porno ha sido marginado en este ensayo. Aun así, es un campo fascinante, que se espera abordar en futuros trabajos.

21 Desde los albores de la Modernidad, la conservadora Europa, mostró una peligrosa fascinación por el otro exótico e hipersexualizado, como lo fue el caso de la Venus de Hotentote a principios del siglo XIX y la homologación del sexo “interracial” con el bestialismo (Echeverría, 2015, p. 408).

22 ¿Pasos hacia la ciber-sexualidad, el cuerpo post-orgánico? Es un tema sugerente y polémico... (Le Breton, 2007, pp. 27-29).

\section{Referencias}

Bauer, J. y Gradus, R. (directores). (2015). Hot girls wanted. Estados Unidos: Two to Tangle Productions.

Bauer, J. y Gradus, R. (directores). (2017). Hot girls wanted: turned on. Estados Unidos: Two to Tangle Productions.

Butler, J. (2007). El género en disputa. El feminismo y la subversión de la identidad. Barcelona, España: Paidós.

Carse, A. L. (1995). Pornography: an uncivil liberty? Hypatia 10, no. 1: 155-82. Recuperado de: http://www.jstor.org/stable/3810463.

Clark, A. (2010). Deseo. Una historia de la sexualidad en Europa. Madrid, España: Cátedra.

Concepcion, C. M. (1999). On pornography, representation and sexual agency. Hypatia 14, no. 1: 97-100. Recuperado de: http://www.jstor.org/ stable/3810625. 
Cortiel, J. (2005). Impure bodies: american pornography and lesbian corporeality. AAA: Arbeiten aus Anglistik und Amerikanistik 30, no. 1/2: 113-25. Recuperado de: http://www.jstor.org/stable/43025750.

Crenshaw, K. (1993). Mapping the differences: Intersectionality, identity politics, and violence against women of color. Stanford Law Review vol. 43: 1241-1299.

Debray, R. (1994). Vida y muerte de la imagen. Barcelona, España: Paidós.

Dyal, R. A. (1976). Is pornography good for you? The Southwestern Journal of Philosophy 7, no. 3: 95-118. Recuperado de: http://www.jstor.org/ stable/43155114.

Echeverría Alvarado, P. (2015). La representación de la mujer en la iconografía de la histeria realizada por Jean Martin Charcot en la clínica de la Salpêtrière: La mirada exaltada del surrealismo y la apropiación alegórica del arte contemporáneo. Tesis doctoral, Universidad Autónoma de Madrid.

Ellis, K., O’ Dair B. y Tallmer, A. (1990). Feminism and pornography. Feminist Review, no. 36: 15-18. Doi: 10.2307/1395105.

Federici, S. (2013). Revolución en tiempo cero. Trabajo doméstico, reproducción y luchas feministas. Madrid, España: Traficantes de sueños.

Fernández, A. M. (2009). Las lógicas sexuales: amor, política y violencias. Buenos Aires: Nueva Visión.

Garry, A. (1978). Pornography and respect for women. Social Theory and Practice 4, no. 4: 395-421. Recuperado de: http://www.jstor.org/ stable/23557105.

Heartney,E.(1991).Pornography.ArtJournal50, no. 4:16-19. Doi: 10.2307/777318. 
Hustler, información editorial. (1999, diciembre). Hustler: 4

Keith, H. E. (2001). Pornography contextualized: a test case for a feministpragmatist ethics. The Journal of Speculative Philosophy 15, no. 2: 12236. Recuperado de: http://www.jstor.org/stable/25670365.

Le Breton, D. (2007). Adiós al cuerpo. México: La cifra total.

Magaña Villaseñor, L. (2018, abril). La estética del cuerpo pospornográfico en la pintura después de la posmodernidad. Cuadernos Intercambio sobre Centroamérica y el Caribe, v. 15, n. 1, 188-204. Recuperado de: https:// revistas.ucr.ac.cr/index.php/intercambio/article/view/32950.

Mohanty, C. T. (2008a). Bajo los ojos de Occidente. Academia feminista y discurso colonial. En: Suárez, Liliana y Aída Hernández (editoras). Descolonizando el feminismo: teorías y prácticas desde los márgenes. Madrid, España; Cátedra: 117-164.

Mohanty, C. T. (2008b). De vuelta a «Bajo los ojos de Occidente»: la solidaridad feminista a través de las luchas anticapitalistas. En: Suárez Liliana y Aída Hernández. Descolonizando el Feminismo. Teoría y práctica desde los márgenes. Madrid, España: Cátedra: 407-464.

Morris, C. (2016, 20 de enero). Porn's dirtiest secret: whatever everyone gets paid, $C N B C$, Recuperado de: https://www.cnbc.com/2016/01/20/pornsdirtiest-secret-what-everyone-gets-paid.html

Preciado, P. B. (2016). Manifiesto contrasexual. Barcelona, España: Anagrama.

Rea, M. C. (2001). ¿What is pornography? Nô̂s 35, no. 1: 118-45. Recuperado de: http://www.jstor.org/stable/2671948.

Retana, C. (2008). Pornografía: la tiranía de la mirada. San José, Costa Rica: Arlekín. 
Saul, J. M. (2006). On treating things as people: objectification, pornography, and the history of the vibrator. Hypatia 21, no. 2: 45-61. Recuperado de: http:// www.jstor.org/stable/3810991.

Sellers, H. (2009). My pornography. Prairie Schooner 83, no. 4: 32-41. http:// www.jstor.org/stable/40640060.

Surnow, R. (2016, 17 de noviembre) Creampie. Cosmopolitan. Recuperado de: http://www.cosmopolitan.com/sexopedia/a8254273/creampie-vaginalanal-sex/

Tong, R. (1982). Feminism, pornography and censorship. Social Theory and Practice 8, no. 1: 1-17. Recuperado de: http://www.jstor.org/ stable/23558968.

Wagoner, B. (director). (2017). After porn ends 2. Estados Unidos: Gravitas Ventures LLC (90 minutos).

Wagoner, B. (director). (2012). After porn ends. Estados Unidos: Gravitas Ventures LLC (94 minutos).

Wasserman, M. (1996). Positive, powerful pornography. Agenda: Empowering Women for Gender Equity, no. 28: 58-65. Doi: 10.2307/4065758.

Whisnant, R. y Mantilla, K. (2007). Pornography and pop culture: backlash and a feminism that is contrary to feminism. Off Our Backs 37, no. 1: 58-

61. Recuperado de: http://www.jstor.org/stable/20838776.

Zawinski, A. (1980). Pornography is violence against women. Off Our Backs 10, no. 7: 8-9. Recuperado de: http://www.jstor.org/stable/25793473. 